\title{
Post-Mortem Artefacts
}

\author{
Ambrish Kaushal ${ }^{1}$ \\ 1Professor and HOD, Department of Oral Pathology, Forensic Odontology, Chandra Dental College and Hospital, \\ Safedabad Barabanki, Uttar Pradesh, India.
}

\begin{abstract}
A post-mortem artefact is any change caused in the body after death that is likely to lead to misinterpretation of medically significant antemortem findings. It is introduced in the period between death and autopsy or during autopsy. The former includes agonal, resuscitation, embalming, exhumation, handling, rigor mortis, postmortem lividity, decomposition, third party, toxicological and miscellaneous artifacts. The latter includes postmortem fractures, skull cap examination, meninges and brain examination, dissection, preservation and miscellaneous artefacts ${ }^{1}$. Postmortem CT is important as it performs the examination rapidly to minimize the degree of changes of decomposition. The absence of blood or gas around thecal sac and skull base depicts artifactual subluxation rather than pathologic. Thermal artifacts include fracture skull, epidural hemorrhage due to intracranially generated steam, extremities fracture due to thermal contraction of tendons and wide splitting of skin and muscles simulating laceration cuts and stab wounds. Gases formed during decomposition include carbon dioxide, hydrogen sulphide, methane and mercaptan. Due to high temperature subcutaneous fat becomes hard and ruptures simulating incised or lacerated wounds. Pink hypostasis is seen in bodies kept in cold storage ${ }^{2}$.
\end{abstract}

Postmortem vibices are tiny spots in dependent parts of body due to rupture of subcutaneous capillaries and smaller venules due to increased intravascular pressure from blood pooling and can be mistaken for bruises. Patchy lividity over neck and face, medial side of thighs, occipital area is misinterpreted as bruises and misdiagnosed as strangulation, sexual assault and blunt trauma to head respectively. During rigor mortis the superficial venous blood cannot drain into deeper venous system which can appear as patchy lividity over upper chest and neck misinterpreted as contusions of throttling. In hanging, postmortem anal bleeding from deceased may be due to hemorrhoids if suspension duration is long. Gravitational forces due to upright position of the body facilitates postmortem per rectal bleeding from ulcerated haemorrhoids ${ }^{3}$. No topic in forensics has been investigated thoroughly as that of determining the time of death on the basis of postmortem findings. Macroscopic observations together with sense of ingenuity and lateral thinking form the keystones of past forensic practice. The application of both molecular and histological diagnostic techniques are gaining popularity as essential armaments to exclude artefacts ${ }^{4}$.

\section{REFERENCES}

[1] Sutherland T, O'Donnell C. The artefacts of death: CT post-mortem findings. Journal of Medical Imaging and Radiation Oncology 2018;62(2):203-10.

[2] Sharma G, Singh H, Mittal S, et al. Dilemma for autopsy surgeon. JIAFM 2007;29(4):68-71.

[3] Thejaswi HT, Rayamane AP, Puneeta R, et al. Artefacts and its medico-legal problems. Journal of Forensic Medicine Science and Law 2013;22(2):1-6.

[4] Pearson GR, Logan EF. The rate of development of postmortem artefact in the small intestine of neonatal calves. Br J Exp Path 1978;59(2):178-82.
Corresponding Author:

Ambrish Kaushal,

Professor and HOD,

Chandra Dental College and Hospital,

Safedabad Barabanki,

Uttar Pradesh, India.

E-mail: ambrish_kaushal@rediffmail.com

DOI: $10.14260 / \mathrm{jemds} / 2019 / 636$

Financial or Other Competing Interests: None.

How to Cite This Article:

Kaushal A. Postmortem artifacts. J. Evolution Med. Dent. Sci. 2019;8(38):2929,

DOI: $10.14260 / j e m d s / 2019 / 636$

Submission 12-07-2019,

Peer Review 06-09-2019,

Acceptance 12-09-2019,

Published 23-09-2019. 